\title{
Gold and US money demand
}

\author{
Samih Antoine Azar* \\ Haigazian University, Beirut, Lebanon
}

Received: 29 March 2018

Revised: 03 September 2018

Accepted: 03 September 2018

\begin{abstract}
This letter is about the long run cointegration relation of the US money demand function that incorporates a gold price variable. A three-equation model is jointly constructed and estimated. The first equation has real gold prices, as a dependent variable, and real money, the real dollar index, a scale variable, and the lagged cointegration residual as independent variables. All the variables are in first-differences of the logs except the cointegration residual. The second equation is the cointegration regression with the same variables in log levels. And the third equation is a GARCH model of the conditional variance of residuals. Two different scale variables are chosen: the industrial production index and the real personal disposable income. Both variables produce close estimates. All coefficients are of the correct expected sign and are statistically different from zero. The evidence presented is highly supportive of the model. In particular we find long run money neutrality, and long run constant economies of scale for both scale variables. Moreover, both the short run and long run elasticities of the real dollar index are also unitary. Surprisingly real money and each one of the two scale variables, have no short run effects on the log of real gold prices, but have only long run effects. One can no more exclude gold from the US money demand without incurring a mis-specification. In this regard gold may be the missing variable that produces the structural breaks found in the literature.
\end{abstract}

Keywords: US money demand; gold prices; cointegration; GARCH; money neutrality; constant economies of scale; short run and long run

JEL Classification Codes: E41, E44, E30, C51, C58, C12

\section{Introduction}

Gold has a special standing in everyday life. Gold serves as an investment outlet, is regarded as a commodity, has industrial usage, is a store of value, is an ideal gift in special celebrations, and is highly esteemed by ordinary people in most developing countries, like in India, or in Egypt. Moreover some refer to gold as a currency since it was anchored to the US dollar, and was widely traded in place of the US dollar, before and after the Bretton Woods agreement.

\footnotetext{
*E-mail: samih.azar@ haigazian.edu.lb.
}

Citation: Azar, S. A. (2018) Gold and US money demand, Economics and Business Letters, 7(3), 108-114. 
Gold is currently believed to be a hedge and a safe haven (Baur and Lucey, 2010; Ciner et al., 2013; O'Connor et al., 2015). A hedge should be negatively correlated with the asset in the exposed position and act as a strong diversifier or be positively correlated and act as a weak diversifier. A safe haven should be either negatively or should be uncorrelated with the exposed asset in times of turmoil. However, whether gold is an inflation hedge and a forecaster of inflation is still debatable. This paper will start by assuming that there is no long run relation between US money supply and gold prices. In fact Batten et al. (2014) find that gold prices and the US Consumer Price Index were not cointegrated, meaning they do not move in tandem in the long run. Since nominal money supply is found to be non-stationary, since nominal gold prices are also non-stationary, and since the ratio of money supply to gold prices is again non-stationary, it is deduced that gold prices and nominal money cannot be anchored to each other in the long run. Otherwise, the ratio of money supply to gold prices would be stationary and the two variables would be co-integrated and, hence, would move in unison in the long run. This does not mean that real money and real gold prices are not related in the long run. In fact they are related when allowance is made for other controlling factors. This paper will show that real money and real gold are indeed cointegrated, and that the relation is proportional. This result means that it is no more permissible to omit gold from the demand for money function. Additionally, omitting gold may explain the structural breaks that the literature finds in the data. Finally, the theoretical framework of overshooting of flexible commodity prices is once again validated.

The paper has five sections in the following sequence: the introduction, the literature survey, the model formulation, the empirical results, and the conclusion. The model is a typical money demand equation. However, it is estimated jointly from three equations to be expressed in a following section. The empirical results show that, in absolute values, all three elasticities are insignificantly different from +1 . These three elasticities are those against the real price of gold and are defined as: the elasticity with respect to the scale variable, the elasticity with respect to the real effective exchange rate of the dollar, and the elasticity with respect to the real money supply. Not only are these effects unitary on an individual basis, but they have also jointly a unitary effect. In particular real money impacts proportionately real gold prices. The paper concludes that monetary conditions in the US determine quite well the real price of gold in the long run.

\section{Survey of the literature}

Gold, by being an investment outlet, and by being priced in auction markets, is an extremely flexible financial indicator. When consumer prices are sticky foreign exchange rates will overshoot in the short run the expansion in the money supply and will converge to the PPP (Purchasing Power Parity) equilibrium in the long run (Dornbusch, 1976). Frankel (1986) generalizes and extends this notion by assuming that commodity prices, being flexible like foreign exchange rates, will overshoot in the short run the creation of money until consumer prices catch up in the long run. The price level is a weighted average of commodity prices and consumer prices, and is always determined by the money supply, after controlling for other factors. The overshooting theory is plausible and it did receive empirical support (Browne and Cronin, 2010). These authors used commodity indexes to take the place of the commodity variable. Azar (2012a, 2012b, 2012c) echoed these results by considering other commodity indexes, and spot and futures prices of individual commodities. Since gold is a commodity one would expect that the monetary model will hold for this particular asset. This is the purpose of this paper: to check whether real money supply and real gold prices are cointegrated after controlling for other factors.

Although the purpose of the paper is to show whether gold enters in the US demand for money, it is instructive to summarize the literature on US money demand in general. This will 
serve to make the point that omitting gold from the US money demand leads to mis-specifications, and may explain why the US money demand has undergone structural breaks, as evidenced by Choi and Jung (2009) and, later, by Rao and Kumar (2011), and is described by two separate regimes (Davis et al., 2013). Related to this literature Li and Mohan-Neill (2017) find that, by separating the sample between expansion and recession the cointegration regression produces better inferences. These authors find also that during recessions the demand for money is insensitive to interest rates, implying the existence of a liquidity trap when interest rates are near zero. Azar (2014) by estimating two versions of the demand function, one related to interest rates as such, and the other related to interest rates in log, finds that the second version is better specified. Azar concludes that this is evidence for a liquidity trap. Moreover, scrutiny of gold fluctuations over the sample period reveals that gold prices have reacted excessively at the time of the structural breaks identified in the literature. Hence, omitting or ignoring gold prices in the US money demand would likely lead to structural breaks. That is why, in this paper, the model is stable. This can be ascertained by the fact that the lagged cointegration residual, or the ECM variable, produces a statistically highly significant coefficient.

\section{The model}

We start by the conventional money demand function, with the price of gold $\left(G_{t}\right)$ deflating the US nominal money supply $\left(\right.$ mone $\left._{t}\right)$. And both are deflated by the US Consumer Price Index $\left(P_{t}\right)$. We add to the function a real scale factor $\left(\right.$ scale $\left._{t}\right)$, which can be either the US Industrial Production Index, which is a real term indicator, or the US real personal disposable income, another real term indicator. Since gold is priced in US dollars, and is still used as a "currency" because of its property as a store of value (Fei and Adibe, 2010), we include the trade-weighted dollar exchange rate deflated by the US CPI $\left(\right.$ dollar $\left._{t} / C P I_{t}\right)$. When the dollar loses value it is sensible to assume that it will be substituted by gold, driving up the price of the latter (O'Connor, 2015). Hence we would expect a depreciation of the US dollar to increase the price of gold. Equations (1) below is the derivation of the cointegration regression that summarizes the long run model:

$$
\begin{gathered}
\log \left(\text { money }_{t} / G_{t}\right)=\log \left(\frac{\left(\text { money }_{t} / P_{t}\right)}{\left(G_{t} / P_{t}\right)}\right) \\
=\pi_{0}+\pi_{1} \log \left(\text { dollar }_{t} / P_{t}\right)+\pi_{2} \log \left(\text { scale }_{t}\right)+\epsilon_{t} \Rightarrow \\
\log \left(G_{t} / P_{t}\right)=\lambda_{0}+\lambda_{1} \log \left(\text { dollar }_{t} / P_{t}\right)+\lambda_{2} \log \left(\text { scale }_{t}\right)+\lambda_{3} \log \left(\text { money }_{t} / P_{t}\right)+\varepsilon_{t} \\
\text { with: } \lambda_{0}=-\pi_{0} ; \lambda_{1}=-\pi_{1}<0 ; \lambda_{2}=-\pi_{2}<0 ; \lambda_{3}=1
\end{gathered}
$$

Since there is evidence of conditional heteroscedasticity a GARCH model is estimated jointly. Moreover the cointegration residual $(\varepsilon)$ is also estimated jointly with the model and its appended GARCH model.

The final joint regression, composed of three equations, is estimated jointly by non-linear least squares, and is as follows (with $\Delta$ being the first-difference operator):

$$
\begin{gathered}
\Delta \log \left(G_{t} / P_{t}\right)=\beta_{1} \Delta \log \left(G_{t-1} / P_{t-1}\right)+\beta_{2} \Delta \log \left(G_{t-2} / P_{t-2}\right)+\alpha \Delta \log \left(\text { dollar }_{t} / P_{t}\right) \\
+\delta \varepsilon_{t-1}+\vartheta_{t} \\
\varepsilon_{t-1}=\log \left(G_{t-1} / P_{t-1}\right)-\lambda_{0}-\lambda_{1} \log \left(\text { dollar }_{t-1} / P_{t-1}\right) \\
-\lambda_{2} \log \left(\text { scale }_{t-1}\right)-\lambda_{3} \log \left(\text { money }_{t-1} / P_{t-1}\right) \\
\sigma_{t}^{2}=\theta_{0}+\theta_{1} \vartheta_{t-1}^{2}+\theta_{2} \sigma_{t-1}^{2}
\end{gathered}
$$

This set of 3 equations can be formulated in a two equation model, eliminating the lagged cointegration residual, and estimating the coefficients by non-linear least squares: 


$$
\begin{gathered}
\Delta \log \left(G_{t} / P_{t}\right)=\beta_{1} \log \left(G_{t-1} / P_{t-1}\right)+\beta_{2} \Delta \log \left(G_{t-2} / P_{t-2}\right)+\alpha \Delta \log \left(\text { dollar }_{t} / P_{t}\right) \\
+\delta\left[\log \left(G_{t-1} / P_{t-1}\right)-\lambda_{0}-\lambda_{1} \log \left(\text { dollar }_{t-1} / P_{t-1}\right)\right. \\
\left.-\lambda_{2} \log \left(\text { scale }_{t-1}\right)-\lambda_{3} \log \left(\text { money }_{t-1} / P_{t-1}\right)\right]+\vartheta_{t} \\
\sigma_{t}^{2}=\theta_{0}+\theta_{1} \vartheta_{t-1}^{2}+\theta_{2} \sigma_{t-1}^{2}
\end{gathered}
$$

Notice in equations (3) the originality of the specification, which consists in the estimation of the Error-Correction Model (ECM), in first-differences of the variables, jointly with the cointegration regression, and together with the $\operatorname{GARCH}(1,1)$ model. Note also the inclusion of two autoregressive variables. Each one of these variable is found to be statistically different from zero, but the sum of their coefficients is insignificantly different from zero, implying that real gold prices are not predictable from their past history.

\section{The empirical results}

The empirical results are divided in two tables. Table 1 provides for the estimation of the model, and Table 2 covers some interesting hypotheses tests. In Table 1 two joint regressions are reported. In both the real price of gold is the dependent variable, and in both the real dollar index is included. An increase in the US dollar index is an appreciation of the US dollar. The difference in the two regressions is in the scale variable adopted. Two scale variables were selected, which espouse aggregate demand and are available in a monthly frequency, and these are: the US Industrial Production Index, and the real personal disposable income. The money supply is taken to be the MZM constant maturity money supply. The CPI is the comprehensive CPI, which includes all items, especially food and energy. All data are retrieved from the web site of the Federal Reserve Bank of Saint Louis, and span the monthly period between February 1973 and February 2018, making a total of 541 observations.

All variables were tested for stationarity around a trend, and found to be non-stationary in log-levels, and stationary in first-differences. Three unit root tests were applied: the Augmented Dickey-Fuller (ADF) test, the Phillips and Perron (PP) test, and the KPSS test. The test results are concordant. The log-level variables are non-stationary, but they become stationary in firstdifferences.

The two different scale variables do not make a difference in what concerns the magnitude and significance of their estimated regression coefficients. The impact of real money is proportional and positive. The impact of the US real dollar index is negative, as expected. So is the impact of the scale variable, also as expected. All these relations happen in the long run, in the cointegration regression. Moreover the lagged cointegration residual is negative, as expected, and implies a speed of adjustment from the short run to the long run between 2.67 and 3.01 years, which are reasonable figures. Additionally this variable carries high statistical significance with t-statistics of -3.45 and -2.97 depending on the scale variable used. It is interesting to note that in the short run only the first-difference of the dollar index enters the short run regression. The other two variables are the first lag and second lag of real gold prices.

The hypothesis tests implemented are identified by 6 hypotheses. The first is about the coefficients on the two lagged dependent variables. The first lag carries a positive and significant coefficient, implying mean reversion or overreaction. And the second lag carries a negative and significant coefficient, implying mean aversion, and under reaction. The sum of the two is insignificantly different from zero, implying the absence of dependence on lagged values within 2 months. Four coefficients are of interest. The first one is the negative and significant coefficient on the real dollar index in the short run regression, which is found to be insignificantly different from -1 . The second coefficient, on the real money variable in the long run cointegraton regression, is significant, positive, and insignificantly different from +1 . The third and fourth coefficients in the long run cointegration regression, on the scale variable and on the real 
dollar index, are negative, significant, and insignificantly different from -1. Finally, all four coefficients or elasticities in absolute values are jointly insignificantly different of +1 . The results, therefore, support strongly the hypothesis of unit elasticity for all independent variables. These results are extremely reasonable and imply that the model is well formulated and properly specified. This is true especially because the standardized residuals, and their squares, do not have serial dependencies as evidence from the Ljung-Box Q-statistics. Comparing the two regressions, with the two scale variables, the regression with the US industrial Production Index is marginally better as evidenced by the Schawrz information criterion and the log likelihood statistic, despite having a lower adjusted R-Square.

Table 1. OLS Joint estimation of equations (2) in the text.

\begin{tabular}{|c|c|c|}
\hline parameter & $\begin{array}{l}\text { scale: Industrial } \\
\text { Production Index }\end{array}$ & $\begin{array}{c}\text { scale: real personal } \\
\text { disposable income }\end{array}$ \\
\hline$\beta_{1}$ on $\Delta \log \left(G_{t-1} / P_{t-1}\right)$ & $0.125183(2.815754)$ [0.0049] & $0.128798(2.856247)[0.0043]$ \\
\hline$\beta_{2}$ on $\Delta \log \left(G_{t-2} / P_{t-2}\right)$ & $-0.127876(-2.895861)[0.0038]$ & $-0.125190(-2.778769)[0.0055]$ \\
\hline$\alpha$ on $\Delta \log \left(\right.$ dollar $\left._{t} / P_{t}\right)$ & $-0.965329(-8.914908)[0.0000]$ & $-0.966780(-8.899952)[0.0000]$ \\
\hline$\delta$ on $\varepsilon_{t-1}$ & $-0.031255(-3.450643)[0.0006]$ & $-0.026902(-2.967498)[0.0030]$ \\
\hline$\lambda_{0}$ constant & $4.296556(2.474919)[0.0133]$ & $10.67997(2.038727)[0.0415]$ \\
\hline$\lambda_{1}$ on $\log \left(\right.$ dollar $\left._{t-1} / P_{t-1}\right)$ & $-1.163980(-2.182675)[0.0291]$ & $-1.472747(-2.583870)[0.0098]$ \\
\hline$\lambda_{2}$ on $\log \left(\right.$ scale $\left._{t-1}\right)$ & $-1.731329(-2.830338)[0.0046]$ & $-1.651062(-2.185157)[0.0289]$ \\
\hline$\lambda_{3}$ on $\log \left(\right.$ money $\left._{t-1} / P_{t-1}\right)$ & $1.132369(3.226502)[0.0013]$ & $1.353207(2.549918)[0.0108]$ \\
\hline$\theta_{0}$ constant & $0.000077(1.995099)[0.0460]$ & $0.0000764(2.005545)[0.0449]$ \\
\hline$\theta_{1}$ on $\operatorname{ARCH}(1)$ & $0.153469(2.478597)[0.0132]$ & $0.150493(2.367223)[0.0179]$ \\
\hline$\theta_{2}$ on $\operatorname{GARCH}(1)$ & $0.805074(12.83794)[0.0000]$ & $0.808239(12.56155)[0.0000]$ \\
\hline Adjusted $R^{2}$ & 0.169479 & 0.174018 \\
\hline loglikelihood & 1004.838 & 1003.423 \\
\hline Schawrz criterion & -3.586780 & -3.581549 \\
\hline$Q(3)$ & 0.106 & 0.142 \\
\hline$Q(6)$ & 0.227 & 0.265 \\
\hline$Q(12)$ & 0.028 & 0.044 \\
\hline$Q^{2}(3)$ & 0.886 & 0.897 \\
\hline$Q^{2}(6)$ & 0.110 & 0.076 \\
\hline$Q^{2}(12)$ & 0.147 & 0.093 \\
\hline normality test & 0.000000 & 0.000000 \\
\hline sample size & 541 & 541 \\
\hline sample period & 1973M02 2018M02 & 1973M02 2018M02 \\
\hline speed of adjustment: & 2.666 & 3.097 \\
\hline$-1 / 12 \delta$ (years) & (3.450643) [0.0006] & (2.391472) [0.0171] \\
\hline
\end{tabular}

Notes: Student t-statistics in parentheses with Bollerslev-Wooldridge robust standard errors. Two-tailed p-values in brackets. $\mathrm{Q}(\mathrm{k})$ is the Ljung-Box Q-statistic on the standardized residuals for lag length $\mathrm{k} . \mathrm{Q}^{2}(\mathrm{k})$ is the LjungBox Q-statistic on the standardized residuals squared for lag length $\mathrm{k}$. P-values are reported for Q and $\mathrm{Q}^{2}$. The normality test is based upon the Jarque-Bera statistic. Actual p-values are reported.

\section{Conclusion}

This letter intended to formulate and estimate an US money demand function, in which gold prices are a variable. The function has real gold prices as the dependent variable, and the real money supply, the real dollar index and a real scale indicator as the independent variables. Two proxies for the scale term are selected: the US Industrial Production Index, and the real personal disposable income. This function is true for the long run, when all the variables are non-stationary, and hold together as a cointegration equation. The short run model is formed out of dynamics and the rate of growth of the real dollar index, including the lagged cointegration residual. 
We find that all coefficients in absolute values do not depart from +1 . This is true with either one of the two scale variables. Therefore there are constant economies of scale, and money neutrality. These results are concordant with the literature on commodity prices and their relation to the money stock. And the results suggest that, if gold is ignored, the US money demand will be badly specified, and this may explain the presence of structural breaks. Therefore it is not a coincidence that the breaks occur at times when gold overshoots. An extension of the paper is to test the same model with gold ETFs replacing the price of gold. A limitation of the analysis is the omission in the model of other supply and demand factors that determine gold prices, although the R-squares of around $17 \%$ are more than reasonable when monthly financial data are used.

Table 2. Hypothesis tests on the estimated parameters of Table 1. Actual two-tailed p-values are reported.

\begin{tabular}{lcc}
\hline \hline Null Hypothesis & $\begin{array}{c}\text { scale: Industrial } \\
\text { Production Index }\end{array}$ & $\begin{array}{c}\text { scale: real personal } \\
\text { disposable income }\end{array}$ \\
\hline$\beta_{1}+\beta_{2}=0$ & 0.9628 & 0.9469 \\
$\alpha=-1$ & 0.7489 & 0.7810 \\
$\lambda_{1}=-1$ & 0.7586 & 0.3841 \\
$\lambda_{2}=-1$ & 0.2324 & 0.4121 \\
$\lambda_{3}=+1$ & 0.7062 & 0.5555 \\
$-\alpha=-\lambda_{1}=-\lambda_{2}=\lambda_{3}=1$ & 0.2006 & 0.4465 \\
\hline \hline
\end{tabular}

\section{References}

Azar, S. A. (2012a) Commodity price indexes and the US money supply in the long run: further tests, Journal of Financial Markets Research, 4, 35-43.

Azar, S. A. (2012b) Commodity futures and the US money supply, The Empirical Economics Letters, 11(10), 1039-1046.

Azar, S. A. (2012c) Commodity prices and the US money supply in the long run, International Journal of Trade and Global Markets, 5(3-4), 316-335.

Azar, S. A. (2014) The demand for money in the United States, 1959.1-2013.11, International Journal of Finance and Accounting Studies, 2(1), 21-28.

Batten, J. A., Ciner, C., and Lucey, B. M. (2015) Which precious metals spill over on which, when and why? Some evidence, Applied Economics Letters, 22(6), 466-473.

Baur, D. G., and Lucey, B. M. (2010) Is gold a hedge or a safe haven? An analysis of stocks, bonds and gold, Financial Review, 45(2), 217-229.

Browne, F., and Cronin, D. (2010) Commodity prices, money and inflation, Journal of Economics and Business, 62(4), 331-345.

Choi, K., and Jung, C. (2009) Structural changes and the US money demand function, Applied Economics, 41(10), 1251-1257.

Ciner, C., Gurdgiev, C., and Lucey, B. M. (2013) Hedges and safe havens: An examination of stocks, bonds, gold, oil and exchange rates, International Review of Financial Analysis, 29, 202-211.

Davis, B., Karemera, D., and Whitesides, L. (2013) The intertemporal stability of the US money demand function: new evidence from switching regressions, Applied Economics Letters, 20(6), 581-586.

Dornbusch, R. (1976) Expectations and exchange rate dynamics, Journal of political Economy, 84(6), 1161-1176.

Fei, F., and Adibe, K. (2010) Theories of gold price movements: common wisdom or myths?, Undergraduate Economic Review, 6(1), 5. 
Frankel, J. A. (1986) Expectations and commodity price dynamics: The overshooting model, American Journal of Agricultural Economics, 68(2), 344-348.

Li, M., and Mohan-Neill, S. (2017) Interest rates elasticity of money demand in different states of the economy, Banking \& Finance Review, 9(1), 19-26.

O'Connor, F. A., Lucey, B. M., Batten, J. A., and Baur, D. G. (2015) The financial economics of gold-a survey. International Review of Financial Analysis, 41, 186-205.

Rao, B. B., and Kumar, S. (2011) Is the US demand for money unstable?, Applied Financial Economics, 21(17), 1263-1272. 